\title{
Insights from Behavioral Economics to Decrease Pollution and Reduce Energy Consumption
}

\author{
Furui Guan \\ Northeast Yucai School, Shenyang, China \\ Email: 907294801@qq.com
}

How to cite this paper: Guan, F.R. (2019) Insights from Behavioral Economics to Decrease Pollution and Reduce Energy Consumption. Low Carbon Economy, 10, 11-30. https://doi.org/10.4236/lce.2019.102002

Received: March 14, 2019

Accepted: June 8, 2019

Published: June 11, 2019

Copyright $\odot 2019$ by author(s) and Scientific Research Publishing Inc. This work is licensed under the Creative Commons Attribution International License (CC BY 4.0).

http://creativecommons.org/licenses/by/4.0/

\begin{abstract}
This paper is written to help relieve existing environmental problems. This paper focuses on how insights from Behavioral Economics can be drawn and affect human behavior in order to reduce pollution and relieve environmental problems. This research involves several interviews with government officials involving the preservation of energy and water, managers of environment-related corporations, and leaders of non-government organizations that are trying to reduce pollution and save the environment. Reviewing the existing measures taken by governments, this paper analyzes different points of views and approaches and gives several practical suggestions on reducing pollution in the Behavioral Economics point of view, which can be referred to by legislations and other organizations and helps eco-friendly policies to be more efficient and accepted. This paper also evaluates different measures that could be taken and the costs and benefits of different alternatives, bringing a clearer understanding of the impacts of many possible actions that can be both vital and beneficial.
\end{abstract}

\section{Keywords}

Behavioral Economics, Decrease Pollution, Energy Consumption

\section{Introduction}

As we are entering a new age where industrialization, trades, technology development, and resource exploitation are at their peak, the economy and average income, together with social development have had impressive progresses, while our environment is facing serious problems such as different kinds of pollution and large amount of energy consumption that is almost draining the currently 
scarce resource, threatening the further development of human beings from communities to countries and even to the globe as a whole [1].

As the environment is getting more and more vulnerable and polluted, the health of people is seriously harmed and many important industries, for example, agriculture, fishing, astronomy, the development of micro machines, transportation, and even building constructions and designations, are also heavily affected due to the significant drop of available resources and the heavy pollution of the air, water, and plantations, sometimes even the changes in climates [2]. The existing problems are getting more and more severe, harming the health of people, blocking the economic development, causing instability among societies, threatening humanity.

However, while much of the pollution emitted and energy used are necessary for human development, for example, fossil fuels and industrial wastes that are necessary to keep the economy going, a lot of energy consumption and pollution are actually unnecessary and are caused by the psychological biases of people, which, if reduced, can strongly mitigate the environmental problems we are facing [3]. So, apart from pure technological development that directly solves the environmental problems by ways like creating more resources or purifying the polluted Earth, etc., methods involving insights from Behavioral Economics that drive people to be greener can also be a focus of our efforts in solving the environmental problems, which can both save large amount of money for individuals, corporations, and even governments, and provide us with a suitable environment for living, working, and developing [4].

Many actions have already been taken by different organizations and governments, most having a considerable influence and certain benefits. Many ideas have also been proposed [5]. All of the existing solutions and their results can serve as desirable references for those who are intending to solve the problems. However, since the situations vary from place to place and the solutions working at one place might not be as effective as expected in another, it is relatively hard to come to a specific universal solution for the high level of pollution and energy consumption [6].

\section{Major Types of Pollutions and Environmental Issues}

The major problems we are facing are: water pollution, air pollution, and huge energy consumption.

\subsection{Water Pollution}

According to Wankai Guan, the former official at Department of Water Resources of Liaoning Province, chemical emission is one of the most harmful sources of water pollution. With countless factories dealing with the industrial waste by simply pouring it into the nearby rivers and lakes, the water system is becoming more and more polluted [7].

The water system is already vulnerable, and, with tons of acidic or basic, and 
even toxic industrial waste being poured into the rivers, is at the edge of collapse. The government has passed several laws to confine waste emission and support purchasing eco-friendly producing equipment. The water pollution, however, is not reduced enough [8].

\subsection{Air Pollution}

Air pollution is a serious problem that almost everyone in China is facing. The key factor contributing to air pollution is the consumption of fossil fuels. Most cars burn gasoline, most power stations burn coals to produce electricity, the Central-heating in the northern part of China burns coals. With the development of industry, more and more pollutants are emitted into the atmosphere, together with more carbon-dioxide, which is stated as "the leading pollutant" in National Geographic, which results in global warming [9]. Air pollution costs the world economy $\$ 5$ trillion per year as a result of productivity losses and degraded quality of life, according to a joint study by the World Bank and the Institute for Health Metrics and Evaluation (IHME) at the University of Washington [10].

\subsection{Energy Consumption}

Mr. Guan pointed out that the biggest concern in energy consumption is that many people are consuming more energy than they have to, wasting the scarce resources and threatening the environment. Facing air pollution, carbon emission, global warming and many other environmental issues, we must take measures to reduce energy consumption, at least to the actually needed amount [11].

A balance between the environment and industrialization must be reached. Insights from Behavioral Economics can be utilized to moderate people's behavior and the opinions of many to reduce pollution and energy consumption, even to the tiniest extent [12].

\section{Impacts and Problems of Individuals, Corporations, and Governments}

There are three roles in today's economy that are related to pollution: individuals, corporations, and governments [13].

\subsection{Individuals}

Most individuals are causing extra pollution and energy consumption because of laziness and unawareness. Many people are just too lazy to take any action to be eco-friendlier. While switching off the light when one leaves is a simple thing that requires virtually no effort, many people just do not do that because they are too lazy to reach the switch [14]. While garbage classification is a beneficial action both for the individuals and for the environment, lots of people still stick to the 'traditional' method of putting all the garbage into one big bag and then dump them simply because classifying the garbage requires time and effort [15]. 
And in some other cases people just cannot see eco-friendliness of some green actions, for example, using phosphorus-free laundry soap powder. Other factors may also lead to individuals' harmful behaviors [16].

\subsection{Corporations}

Most corporations are causing pollution for profits. While sometimes there are certain policies trying to limit factory emission, there are always 'gray areas' within the policies that can be taken advantage of by the corporations if the corporations think being eco-friendly actually makes them lose money. In short, the corporations are always pursuing profits [17].

In most cases, being eco-friendly and consume less energy saves money, so corporations are supposed to be happy with being eco-friendly. But sometimes some psychological effects may affect their judgement and cause them to make wrong decisions. Unawareness is also an important factor causing corporation pollution [18].

\subsection{Governments}

Governments play a very important role in policy-making. Our government has already realized the issue we are facing and the importance to take actions. But meanwhile, our government is not taking enough actions, and there is still a lot to be learnt from other developed countries. The policies are not strict enough, and the government agencies are not carrying them out in the proper way. According to a survey conducted by tech.ifeng.com, $63.29 \%$ of participants think that a large amount of e-waste is due to the lack of supervising from the government.

While these problems are long term and take time to be solved, the government can make use of insights from Behavioral Economics to structure its policies, websites and announcements to help them to be better accepted.

\section{Existing Problems}

While it is a common knowledge that we should protect the environment and a lot of actions can be taken to reduce pollution and energy consumption without causing any great losses, and sometimes taking those actions actually brings benefits, most of the people still choose the "traditional" ways and harm the environment. This kind of phenomenon can be explained with insights from Behavioral Economics [19].

According to Behaviour Change and Energy Use by Cabinet Office Behavioural Insights Team, "the behaviours of individuals can deviate greatly from a standard rational choice model, in which people objectively weigh up the costs and benefits of investing time and money into 'greening' their homes and being more energy efficient" [20]. In many cases, people are not behaving rationally and may make mistakes in weighing the pros and cons of certain actions, which results in some extra energy use and environmental pollution. Since we are using 
heuristics (shortcuts), according to Daniel Kahneman, to think, our perception might not be the truth and our choices may not be cost-effective. And here are some points about why people make such mistakes.

\subsection{Discounting the Future}

According to Behaviour Change and Energy Use by Cabinet Office Behavioural Insights Team, people tend to favor immediate gains over long-term benefits. For example, one might prefer to get 5000 dollars right away rather than get 6000 dollars in 3 years [21]. This kind of issue is a great factor that leads to the result that many people do not purchase energy-efficient products even if they can save a relatively large amount of energy consumption, which saves a noticeable amount of money in the long term. Because most people, when considering purchasing an energy-efficient product, focuses more on the upfront cost instead of the long-term benefits, which may result in some mistakes in weighing the costs and benefits, and, thus, leads to the low consumption of energy efficient products [22].

\subsection{Status Quo Bias}

As Daniel Kahneman and his other colleagues have pointed out, there is a preference for those pre-set conditions among people, which means that in many cases people are unwilling to make changes. And this kind of phenomenon is called the "status quo bias". For example, in the book "NUDGE Improving Decisions About Health, Wealth, and Happiness" by Richard H. Thaler and Cass R. Sunstein, the authors included several survey results showing that a larger amount of organ donors are found in states where "being an organ donor" is the default than in states where "not to be an organ donor" is the default, indicating that people tend to stick with the defaults (or status quo) when the cost or effort required to make changes is virtually nothing [23].

The status quo bias may result in individuals' not willing to purchase eco-friendly products even if they do not need to pay for the costs themselves when several existing equipments have to be replaced. The government's legislation might also be affected by status quo bias when considering introducing new policies. And some corporations might be affected by status quo bias when introducing eco-friendly equipment that does not bring huge and immediate profits and thus stick to the old and polluting equipment [24].

\subsection{Social Impact}

Since human beings live within societies and interact with others, one's behaviors are largely influenced by the behaviors and opinions of those around him or her, which has been pointed out by Toch. Many people tend to do what others around them are doing, which is some sort of Crowd Psychology. Many people tend to stick to the social norms. This may lead to low participation in garbage classification in China, few purchases of energy efficient products and electric cars, and massive emission within crowds of factories [25]. 
Sometimes, people will not take certain actions if nobody else is doing so, even if the actions are obviously beneficial and universally accepted, simply because they are willing to behave in conformity with others or are afraid to be considered as "the freak". For example, if the whole neighborhood is just throwing their garbage without any classification into a huge trash, and considers this as a norm, one that does carry out garbage classification might stop doing so because it feels weird to be the only one. In addition, in the countryside where almost all farmers set fire on their fields after harvest in order to create more fertile soil, a farmer who does not do so will be widely considered as "an idiot", which leads to a large number of farmers setting fire and polluting the air [26].

The same happens for factories. When all the factories around are emitting a large amount of waste, one factory owner might consider the action of sacrificing profits in exchange for lower pollution as foolish, which causes massive pollution. And this sort of problem can be found in almost every public area in China, causing strong setbacks for individuals to behave in an eco-friendly way.

\subsection{Certainty Effect}

The certainty effect, the idea that people tend to prefer benefits that are certain to benefits that are with possibilities even when the expected value of the option with possibilities is more than that of the "certain" choice, was put forward by Tversky and Kahneman, indicating that human is born with the preference of "risk-averse decisions" and when the possibility is reduced from 100 percent, people may feel certain losses. For example, researches conducted by Kahneman suggest that people are more willing to get a certain amount of money for sure compared to having both the chance to win a larger amount and the chance to get nothing. This is a problem especially severe for governments and corporations.

As we all know, China has been taking several actions to reduce energy consumption and decrease pollution, with regulations and certain punishments and also changes in the market structure, achieving its goal to be eco-friendlier. However, while pollution and energy consumption were actually reduced, some of the regulations and changes being made are not strict enough, not exhaustive enough, with many improvements to be made and many other approaches to be learnt. But the government seems to be happy with such results. This is due to the certainty effect. While taking further actions involves some uncertainty, for example, unemployment, inflation, and factory owners' complaint might occur if the government pushes too hard, the market might be unstable if too many changes are applied, the government prefers the current state where, more or less, there are achievements.

It is the same for corporations. While current methods of production create profits for sure, taking more actions to install eco-friendly equipment and making changes to the production process seem to be unreliable because all the promising profits of the eco-friendly actions are relatively uncertain, involving risks of product quality, energy-saving efficiency, causing fewer corporations to 
try to be eco-friendly.

\subsection{Endowment Effect}

For most things are differently valued by those who have them and by those who wish to get them: what belongs to us, and what we give away, always seems very precious to us.

Aristotle, the Nicomachean Ethics book IX (F.H. Peters translation)

There are ideas since ancient times that people value things more simply because it is theirs. And this idea, or hypothesis, was well studied and put forward by several experts including Daniel Kahneman, Knetsch, Thaler and Beggan, indicating that people tend to spend money or take actions to keep their own things, even if they are acquired not long ago and tend to give a higher evaluation because of "mere ownership."

This is an important factor. While many people are considering replacing the current energy-consuming, waste-producing, and pollution-emitting products with energy-efficient, eco-friendly products, the endowment effect may affect their decisions. While in most cases, the value of the energy consumption saved by installing the replacement actually outweighs the cost of losing the old one, many people, since they have attached more value to those products they already own, actually cannot see the benefits of such replacements and tend to stick with the old ones, causing pollution and waste.

The same is also true for corporations when it comes to replacing the old machines with eco-friendlier ones.

\subsection{Doubt}

While many new, green technologies are being developed, many alternates of traditional products, with the advantages of energy-efficiency, eco-friendliness, and money-saving ability, are rising. And the government has been offering incentives for those who bought the "green cars". However, purchases for such new eco-friendly technologies are relatively small in numbers, even when the monetary benefits are clearly higher than the purchasing cost.

According to m.elecfans.com, many people are concerned with the safety, convenience, and reliability of such new technologies. That is to say, many people nowadays still do not trust the new technologies, which is an issue for encouraging people to purchase eco-friendly products.

Taken together, various factors work together, influence each other, causing biases and incorrect perceptions, which affects the choices of people and makes it hard for legislators and other organizations to reduce energy consumption and pollution. The causes of the problem are complicated but solutions can be found focusing on one or several specific points.

\section{How Can Behavioral Economics Help?}

As Lin has pointed out, "Behavioral Economics studies the effects of psycholog- 
ical, cognitive, emotional, cultural and social factors on the economic decisions of individuals and institutions and how those decisions vary from those implied by classical theory". So sometimes people make decisions that are "irrational", which contradicts the conventional idea in economics where people act out of self-interest and always seek the choice with the best benefits. That is the reason why a lot of people, corporations, and even governments make some decisions that cause unnecessary pollution and energy consumption, even when the fact that being eco-friendly and energy-efficient is beneficial is widely accepted.

If we want to take efficient actions to reduce pollutions and energy consumption without needing too many technological breakthroughs or huge changes within our society, approaches from the views of Behavioral Economics would be perfect since, instead of requesting different high-level technologies, they simply focuses on the people's mind and behaviors and their outcomes, which can be easily affected by several relatively small actions such as changing the word choices, website designs or methods to encourage eco-friendly purchases. All those actions can make people cause less pollution and consume less energy than they currently do.

With principles from Behavioral Economics and several other study findings, we are going to be able to alter people's behavior and reduce much pollution and energy consumption, or at least some of them, which is still a big step forward. In order to reduce pollution and energy consumption, many actions can be taken to deal with the existing problems.

\subsection{Incentives}

While some people are unwilling to take certain eco-friendly actions, no matter it's beneficial or not, people tend to be willing to get incentives for their actions. So, regarding many people's unwillingness to purchase eco-friendly products or to take eco-friendly actions and reduce pollution emission, some incentive might work perfectly to lead the people to carry out green actions. The incentives could be monetary, or in other forms. One can receive a discount on their energy or water bills if they have consumed less of the resources compared to the mean. One can receive some special services from the government if they keep being green for a period of time. One can get, maybe days off, incentives from the work place for being eco-friendly. One can also pay fewer taxes on purchasing cars if he or she is buying an electric car. And all those incentives can encourage people to be green.

Regarding the problems caused by the status quo biases, which cause people to be unwilling to purchase eco-friendly products that cost at first but save money gradually simply because they feel an irrational appeal to the current product, the government can set up some sort of incentives to offset the unwillingness to change. For example, a factory will be more than happy to change the original equipment into new, eco-friendly one if they receive money or fewer bills for doing so. The same also works with the problems caused by "discounting the future". While people tend to focus more on the immediate benefit, an upfront 
inventive can never be resisted. Just as the "Green Deal" has done, the government can give incentives in a way of cutting (or even eliminating) the upfront costs of installing green products and get the installing cost back in the following period of time as a little amount of extra charge that is still less than the predicted cost of the original product, which can attract tons of people. Because, facing a large amount of energy consumption saved by installing those products with no upfront cost, everyone gets it that it saves both money and the environment without any cost.

Incentives can also work for the problems of "doubt". For example, one might be more willing to purchase an electric car if it is cheaper, or if it saves the user much more money, of which the value exceeds the "risk" of using a "dangerous product" in the consumer's mind.

Incentives can be given in many different ways. I can be given straight to the individuals that contribute to the green work. It can also be given to a certain community to take advantage of group spirits, encouraging communities to produce less pollution, for example, carrying out garbage classification, using less air conditioning, driving more eco-friendly cars, using less water and electricity, or producing less waste, or using less plastic bags, with promised incentives, which can cause people behave in the way we expect because of their eagerness to bring the benefits to both themselves and the people within their own communities And while everyone in a community is doing the eco-friendly things, one will be more likely to carry out the same things due to the "social influences", which adds to the effectiveness of the incentives and provides oversights for the people, since everyone wants the incentives and will be watching those around him or her and make sure they are also doing the things needed to get the incentives for the whole community.

Incentives can be given as money. Incentives can also be given as a gift, for example, a meal for free, a phone for free, or even several paid days off. And they can even be given as some sort of discounts at certain stores. Since different forms of incentives have their attraction for different groups of people, the diversity of the forms of incentives should be appreciated.

While proper incentives encourage people to be green, several improper incentives might not have such great outcomes. Giving too many incentives might lead to losses for the government or the related companies that outweighs the benefits generated by being greener. And giving incentives that are too small might not have a desirable effect since a lot of people just do not care about the "small stuff". And proper forms of incentives are essential for attracting certain groups of people. So, when deciding to use incentives to deal with the problems, policy-makers have to weigh the benefits and risks and think carefully. Researches are also required to make a wise decision.

\subsection{Taking Advantage of Social Impacts}

While sometimes social impacts can cause individuals within a group to not behave in an eco-friendly way because of the crowd psychology, they can also in- 
fluence people in more positive ways using the same mechanism.

Since many people tend to do the same as everyone else around them, a person might be more likely to behave greenly if others around him or her is doing so. So, regulating the main proportion of a group can have an impact on the whole group.

I have conducted a study under the help of the NEYC Students' Union, the NEYC Volunteer Association, and the NEYC Highschool.

The NEYC Volunteer Association has been working on a program that encourages recycling used bottles and paper. Collecting buckets are arranged in each classroom and those classes can send the buckets filled with used bottles or paper to the retrieving center in the school. And the NEYC Volunteer Association takes all the bottles and paper collected to the city department that deals with such materials and gets monetary incentives that are used to purchase toilet paper and chalks for the students in the school.

And all the classes in grade 10 and 11 have been carrying out such recycling processes and everyone was happy to throw used paper and bottles into the certain buckets instead of a random trash can. And we have noticed that almost every new comer does the same even if he or she does not quite understand the purpose of the buckets and the retrieving center. We found that over $83 \%$ of temporary workers and students' parents, and also students coming to the NEYC Highschool for the first time simply to attend some events or contests, have followed the expected use of the buckets even if most of them have no idea what those are for.

By contrast, we have also noticed that in several 12th-grade classes, whose students are under huge pressure of the National College Entrance Exam (Gaokao) and endless homework, many students are not using the buckets. And in these places, we found that newcomers were not following the rules as well as those in Grade 10 and 11.

Liu, president of the NEYC Volunteer Association pointed out that many people were not recycling at first because only a few were doing that, but later, as more and more people started recycling, a lot of people joined the "recyclers" since everyone else was doing so.

So, in most cases, if we can get most of the people within one community or group to be green, the rest will be very likely to do the same even if they are personally not attached to the efforts.

This idea works especially great with the problems caused by the negative "social impacts" and those caused by the "status quo bias", and probably many other factors. No matter what the actions are, as long as they are not morally unacceptable or too personally unappealing, many people will tend to take the actions if others are doing the same. So, while we are always trying hard to make being green appealing and desirable, we can actually change our point, change our approach and make being green some kind of social norm. And people will be green themselves.

People can combine incentives together with "social norms" to set up the 
norm, giving benefits to the people and let them carry out the green behaviors and affect others, which is perfect to set up a social norm within a group of people. Apart from all the benefits of this method, several problems still exist. The following are several problems we are currently facing:

1) It is not easy to make something into a social norm.

2) There might be people that just simply do not care about being the same with others and making any contribution.

3) Social norms need efforts to maintain, which might be costly for the government or other institutions.

So, when deciding to use incentives to deal with the problems, policy-makers have to weigh the benefits and risks and think carefully. Researches are also required to make a wise decision. So, when deciding to use incentives to deal with the problems, policy-makers have to weigh the benefits and risks and think carefully. Researches are also required to make a wise decision.

\subsection{Utilizing Comparison}

While many people tend to do the things that are of the best interest for themselves, people also care about their reputation, or the good comments from others, sometimes it might even be being morally right in their own values. The idea is obvious. While many charity organizations are offering a large amount of money for those who are unemployed, a lot of people still prefer to get a job even if the salaries from the jobs are almost the same as the financial-aids they receive for doing nothing. While several special jobs pay incredibly well, many people (especially in Chinese culture) are not willing to take those jobs because they consider them as "disgraceful." Many people care about being respected.

So, if we can draw several comparisons between different people, or different communities, a lot of people will probably begin to act greenly because they want to be better than the others. When we considering addling comparisons, we can do it in many different fields and many different ways.

1) Comparison on energy consumption.

2) Comparison on pollution emission between corporations.

3) Comparison on eco-friendly product usage.

4) Comparison on pollution reduction between states or cities.

5) Comparison on garbage classification.

All of the above, and many else, can be used in drawing a comparison. And comparison can be drawn not only between individuals or households, but also between corporations and local governments.

While local governments are being compared with others, those who are doing not that great will undoubtedly feel uncomfortable, and will take proper actions to do better. Comparisons between corporations can not only encourage eco-friendly actions among the corporations, but also provide consumers with the information about how green several companies are compared to the others, which can help the consumers to decide when purchasing goods. 


\section{Cultural Revolution}

All of the comparisons, when they cause people to be eco-friendlier, also causes competitions, which might be harmful when being too intense. Too much competition may lead to the tragedies happened during the period of "Cultural Revolution" in China where corporations lie about their gains and losses and people are being too aggressive. So, utilizing comparison requires careful measures and deep researches. Thus, policy-makers have to fully consider the differences between cultures, customs, economic developments, traditional values, political conditions, and local environments before making decisions and utilizing such methods.

\subsection{Utilizing the Status Quo Bias}

As I have previously explained, sometimes people are just unwilling to make changes because they have a wrong idea that the current one they are using brings them more benefits or is just more valuable, which may cause many corporations and households to be unwilling to purchase eco-friendly new products and get rid of the old ones. But if we can take advantage of such biases, a lot can be achieved.

While the status quo caused by the existing pollution-causing equipment can cause people to be unwilling to change, so can those eco-friendly products and measures. The government or legislator can set regulations that request the corporations or other institutes, and even households to use eco-friendly furniture, eco-friendly products, and eco-friendly designs of buildings, even if, in some occasions, they might cause a little bit more. Since the regulations are set up and those eco-friendly products are now the status quo for all the new corporations, they will be more likely to stick to the eco-friendly ones instead of switching to other polluting products and equipment even if they bring more profits. And the same works for individuals and households.

Another way of utilizing the status quo bias is by making tiny changes to some default conditions, for example, room temperature set by air-conditioning. 。

An experiment on the effect of defaults on thermostat settings of OCED employees has been conducted by the OCED, in which the set temperatures were changed and the staffs' behaviors were observed and studied, the results can be shown in Figure 1, Figure 2 and Figure 3.

Adapted from Zack Brown, OCED, "Annex: An experiment to test the effect of defaults on thermostat settings of OCED employees".

Before the experiment was conducted, the preset temperature was 20 degrees Celsius. And the experiment included three groups: one with the same default setting as before, one with the default temperature one degree higher, and one with the default setting one degree lower. As the defaults change, people's behaviors change. The default settings over time and the chosen settings are all listed in the graphs above. The temperature changes during that period of time are also shown in Figure 3, for implications or references. 


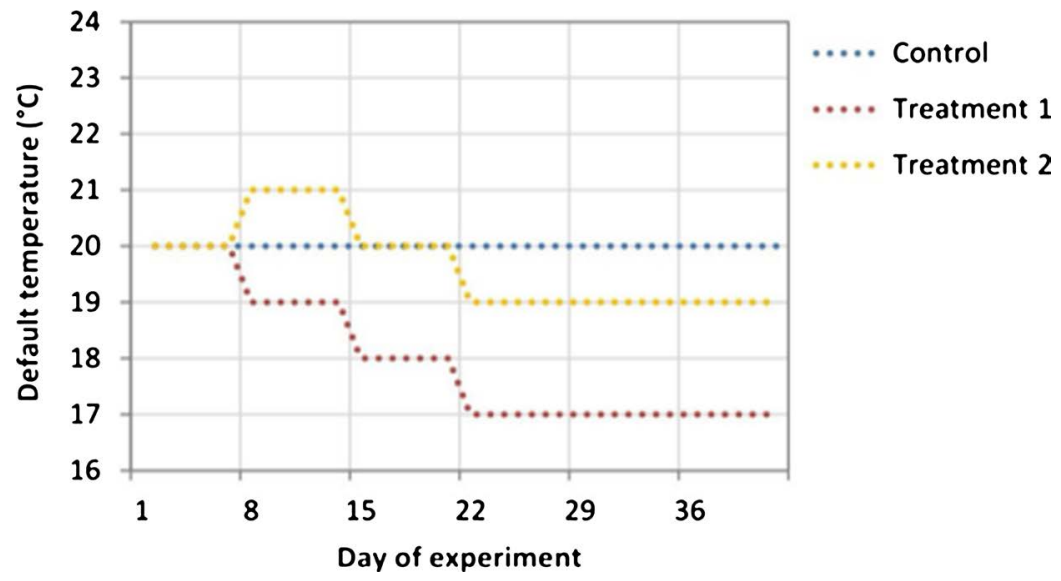

Figure 1. Scheduled changes in defaults for treatment and control groups.

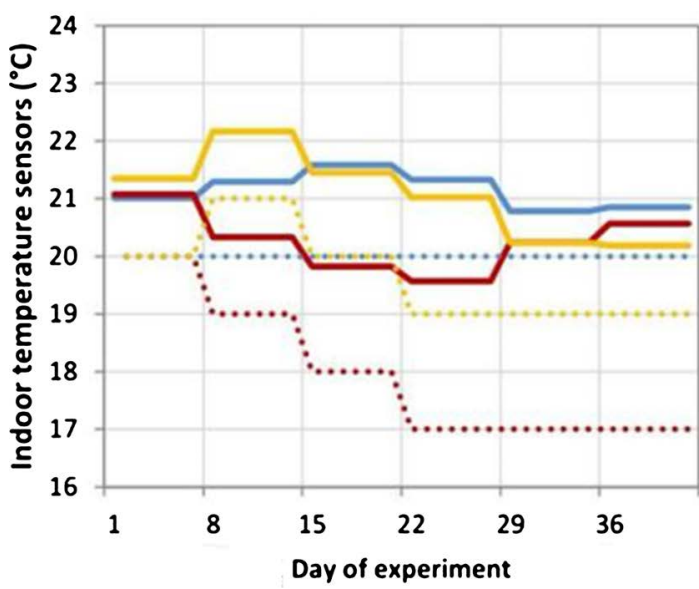

Chosen setting - Control

Chosen setting - Treatment 1

Chosen setting - Treatment 2

Default setting - Control

Default setting - Treatment 1

Default setting - Treatment 2

Figure 2. Changes in the thermostat settings over time for treatment and control groups.

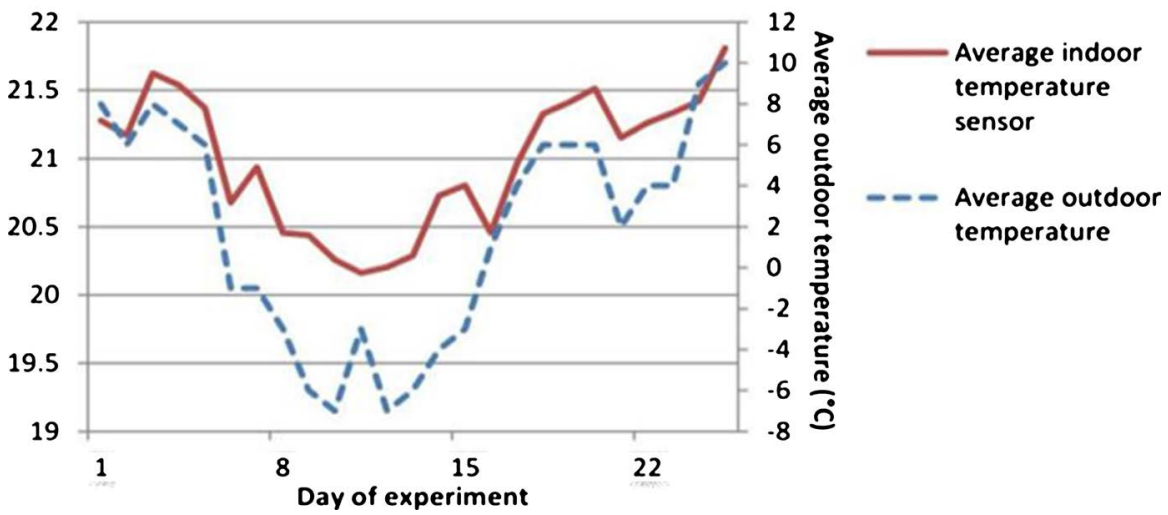

Figure 3. Outdoor and indoor temperature trends during the experiment.

It can be implied, though "limited in scope", from the experiment that "Small reductions in the defaults of office thermostats can lead to lower temperature settings by occupants in the winter heating season, which when scaled up to the whole building translates into lower energy use. However, if the reduction in default temperature is too large, then respondents respond very actively, increase their temperature settings, and behave as if the change in default had never oc- 
curred. In quantitative terms, our results indicate that a reduction of the default temperature from $20^{\circ} \mathrm{C}$ to $19^{\circ} \mathrm{C}$ would decrease energy use, but a reduction to $17^{\circ} \mathrm{C}$ would have no effect", according to the paper written by the researchers.

While it is quite clear that "small reduction in the defaults" has a positive impact on reducing the overall temperature, the reason behind this is relatively unsure, or "require additional experimentation", as the author pointed out. And personally, I think that the effectiveness of small changes is either because the changes are too small to mean anything for the employees but the huge changes make the employees uncomfortable, causing them to make even greater changes to feel better, or because the small changes can be detected but still acceptable and everyone was just too lazy to take any action and make changes, so they just all feel okay with it, while those huge changes make the employees so uncomfortable that they would rather take efforts to make changes, which can be even greater because of the dissatisfaction of the employees. All of the hypothesis needs further study.

But no matter whether the explanations are reliable, the outcome is sure and can be applied to many fields. Legislators or corporations can reduce their pollution emission or energy consumption by changing the defaults, which can lead to a pleasing amount of reduction in pollution and energy consumption. However, the changes in the default settings must be proper and carefully calculated in order to achieve the best outcome.

\subsection{Framing}

In the book Thinking, Fast and Slow, an idea that the "framing" of a certain policy or option actually affects one's decision and perception of the problems was put forward and complemented with several experiments which proved the idea to be valid.

While marketing skills are involved in persuading people to purchase eco-friendly products and act greenly and the "framing" has great impacts on the effect of marketing, the dictions or expressions used to describe the products and the benefits should be taken into consideration to make the eco-friendly products and eco-friendly acts more popular. Legislators can also make changes in the ways they form their announcements, files, or laws to make them more accepted and supported.

In many cases, an eco-friendly product may have pros and cons that almost offset each other, which makes it hard to decide for the consumers whether to purchase such products. With status quo bias and many other factors affecting the choices made by the consumers, special word choices or language structures must be employed to make sure, or at least encourage, that the consumers will make decisions that are good for the reduction of pollution and energy consumption. For example, the advertisements can probably focus more on the benefits of those eco-friendly cars, instead of reminding people of the potential inconvenience caused by the products. Governments, when proposing a green 
policy, can try to estimate the possibility of the success of such a plan, instead of the possibility of failure.

With deeper research and better understanding of the effect of different ways of framing, we can affect people's behaviors by simply changing the way we express it, which costs almost nothing but brings huge benefits to our environment.

\section{Existing Actions}

Facing many problems and possible solutions, many governments, organizations have taken actions to help reduce pollution and energy consumption. The following are several existing examples that can be referred to when making decisions.

\subsection{The Green Deal}

The Green Deal was launched by the UK government to encourage the citizens to be eco-friendlier and more energy-efficient. The government tried to achieve this by providing all of the energy-saving products to the people for free at first. Since a lot of energy consumption was saved with the help of all the products, the people actually got to pay less money for their energy bills. And the government would raise the energy bill a little bit higher, but still less than what the people would have to pay if they had not taken use of the products, to make up for the money they spent on installing the products for the people for free at first. So, basically, people are saving energy cost for free, while they are also contributing to the environment.

With the help of many different government departments and many corporations, the Green Deal covered 45 different types of improvements and saved a large amount of money for both the people and the country, also helping with the environmental well-being.

However, criticism still exists. Many argue, as put forward by Endsreport.com, that such policy takes the companies providing those products and cooperating with the government into a position with no competition, which might harm the equality and the order of the market. The "lack of competition" between suppliers is a problem.

There have also been ideas that the Green Deal added to the budget of the government at the beginning, which is put forward by Madeleine Cuff.

After all, despite all the criticisms, the Green Deal did save lots of energy and money for both the people and the government.

\subsection{China Energy Label}

China Energy Label was launched by the Chinese government, requiring all the producers and importers to evaluate the energy-effectiveness of the products and print a little sign showing the energy-saving performance level on the products.

The performance is divided into five different levels with level one being the best. And such signs are mandatory throughout the country and must be shown 
or explained on the outer packages or instructions of the products, helping the consumers to understand the products.

As Hu said, such regulations "can effectively notify the consumers about the energy efficiency of the product and guide them to acquire high-quality energy saving devices".

With improvements on technologies, the Energy Labels are working well and making a great difference.

\subsection{Huimin Project}

The Huimin Project started in 2009 and ended in 2013. It was a project launched by the government to encourage the purchases of energy-efficient products. The government offered many subsidies for the consumers who purchased the eco-friendly products, such as air-conditioners or washing machines with greener technologies.

Qiuyue Zhao pointed out in the article "Huimin Project, End in Disputes" that "The Chinese government has allocated 12 billion yuan of subsidy funds to popularize more than 6500 units of energy-saving appliances. The monthly sales volume of energy-saving appliances has increased from 160 million units in June 2012 to 7 million when the policy was ended," indicating the great influence of the project. And $\mathrm{Hu}$ considered the project in her article "How can we use behavioral economics to promote energy saving behavior of the residents through promoting the purchase of energy-saving devices in China?" as "relatively a great success".

Unfortunately, the Huimin Project ended in 2013. Apart from many official documents, Wankai Guan gave a possible explanation that the subsidies were being too costly for the government and by the time it ended, many people had already installed the green products and did not need any more subsidies for other installations.

\section{4. "The Recycle!!!” by NEYC Volunteer Association}

As the vice president of the NEYC Volunteer Association, my team and I have been working on the recycling program I mentioned before. And I have recently gathered some information about the progress and achievements that I did not know before from the president of the NEYC Volunteer Association, Jingjing Liu.

We encourage the students to recycle used bottles and paper by promising that all of the benefits made by recycling go straight to the students, for example, purchasing toilet paper in the public washrooms, which is very rare in public schools in small cities in China, purchasing snacks on holidays, and using the money as starting funds for school volunteer tours, a nice trip doing volunteer work and having fun while escaping from school that everyone enjoys. And we really did it. With other means like posters and presentations or public speeches, we are able to save tons of trees every year, and, as is mentioned, the participation rate within the students that are not bothered by upcoming exams is quite impressive. "Everyone is happy with it, and they are all doing great", Said Liu.

This is an act that both encourages green actions and prompts students' sense 
of responsibility.

\section{Practical Solutions}

\subsection{Incentives for Companies That Produce Less Pollution}

With all of the former analyses and experiments, it is quite clear that incentives should be given to the companies that are being greener than their peers, in a proper and more effective way, in order to reduce pollution and energy consumption, together with other actions that are using the ideas from Behavioral Economics that might be helpful.

The government can alter all of the online markets and use the "framing" skills to make the green products more popular, or cut taxes for the companies on purchasing green equipment.

Meanwhile, faced with lower taxes, lower prices and better "feeling", the companies will be more likely to purchase such products. To make up for the lost tax money, the government can ask the green product producer for some money since it has helped the producers to raise sales and get profits.

So, such an idea provides a chance to both promote the economy and save the environment.

\subsection{Forming Social Norms}

Due to the status quo bias and social impacts, people tend to stick to the current state and what others are doing. Hence, it would be beneficial if being green can become some sort of social norm.

The government can make energy-efficient appliances mandatory for newly built buildings and newly formed factories. The government can make garbage classification mandatory, first at government department buildings, and then try to spread it to other places.

The government can also set up more charging devices for electric cars around the city to make electric cars more popular and trusted. Though such measure may cost much money, the government can achieve the goal in collaboration with firms that produce such devices and firms that produce electronic cars to create some benefit for them, which reduces the expenditure of the team.

\subsection{Reducing Air-Conditioning Usage and Central Heating Temperature in Schools and Working Places}

As the former experiments have shown, adjusting 1 degree Celsius in working places can cause people to consume less energy can create less pollution. This idea can be applied to all of the working places and schools, which can save lots of energy and reduce pollution without affecting the people.

\subsection{Cutting the Upfront Costs for Purchasing Green Products for Households}

With the success achieved by the Green Deal, our government can learn from 
the UK and create our own Green Deal. The same policies may be applied. However, to prevents problems such as no competition between suppliers, the government can start collaborations with the most and dominantly popular online shopping center-Taobao-instead of collaborating with certain brands.

With all of the insights from Behavioral Economics, a lot of changes can be made to reduce pollution and energy consumption. They might not be so huge, but even the tiniest effort has the potential to turn the tide, and even the smallest reduction, if stable since people's cognitions have agreed with such measures, can be a great step forward. And governments, corporations, and individuals should all do their best to be greener and to save our only home. With knowledge and proper actions, we can achieve whatever we want.

\section{Conclusions}

With the different roles of governments, corporations, and individuals in reducing pollution and energy consumption carefully analyzed, many actions can be taken in the perspectives of all of them. While facing different kinds of pollution and large energy consumption caused by cognitive biases and many other problems in Behavioral Economics, insights from Behavioral Economics can be used to correct such biases or make being green more desirable.

In this paper, I have analyzed the current situation of pollution in our country and the roles of the government, corporations and the individuals. With major environmental problems we are facing carefully analyzed, ideas about what are causing such problems and why many more beneficial alternatives are not utilized are given based on insights from Behavioral Economics. With studies conducted and several interviews with related authorities or organization leaders, several solution theories were put forward in the view of Behavioral Economics, which can be of great help for those working on the green career.

Many existing actions taken by governments and organizations are also studied and analyzed, which serves as reference and experience for others. Many practical ideas are also proposed to reduce energy consumption and pollution.

It is sure that many actions can be taken from the insights of Behavioral Economics to reduce pollution and energy consumption. However, the exact methods have to be discovered and explored by the legislators since the conditions are different from place to place, even within the same city. Differences exist in culture, wealth, population structure, environment, local policies, education standard, and even infrastructure and so on. Reaching a solution practical for all places is almost impossible, but many basic ideas and principles can be applied, with proper modification according to local condition, to help reduce pollution and energy consumption. Proper research and tests are required before making a decision.

After all, with many effective ideas in mind, people can take proper actions after confirming the practicality and benefits of those actions, and reduce pollution and energy consumption from the behavioral view to create a greener envi- 
ronment for all of us.

\section{Acknowledgements}

\section{SPECIAL THANKS TO}

1) Horizon Academic Research Program,

2) Edoardo Gallo, best professor ever,

3) Daniele, best TA ever,

4) Ellen Gao, perfect organizer,

5) Wankai Guan,

6) Jingjing Liu,

7) Northeast Yucai School,

8) NEYC Volunteer Association,

9) NEYC Students Union,

10) Unlimited passion of the author.

\section{Conflicts of Interest}

The authors declare no conflicts of interest regarding the publication of this paper.

\section{References}

[1] National Geographic (2016) Air Pollution Causes, Effects, and Solutions.

[2] World Bank, Institute for Health Metrics and Evaluation at University of Washington-Seattle (2016) The Cost of Air Pollution: Strengthening the Economic Case for Action (PDF). The World Bank, Washington DC, 12. https://doi.org/10.1596/25013

[3] McCauley, L. (2016) Making Case for Clean Air, World Bank Says Pollution Cost Global Economy \$5 Trillion. Common Dreams.

[4] Survey: $63 \%$ of Participants Think Lack of Governmental Supervise Causes Massive e-Waste. http://Tech.ifeng.com

[5] Cabinet Office Behavioural Insights Team (2011) Behaviour Change and Energy Use.

[6] Toch, H. (1988) Psychology of Crowds Revisited. PsycCRITIQUES, 33, 954-955. https://doi.org/10.1037/026204

[7] Kahneman, D. (2011) Thinking, Fast and Slow. Farrar, Straus and Giroux, New York.

[8] Kahneman, D., Knetsch, J.L. and Thaler, R.H. (1991) Anomalies: The Endowment Effect, Loss Aversion, and Status Quo Bias. Journal of Economic Perspectives, 5, 193-206. https://doi.org/10.1257/jep.5.1.193

[9] Tversky, A. and Kahneman, D. (1991) Loss Aversion in Riskless Choice: A Reference-Dependent Model. The Quarterly Journal of Economics, 106, 1039-1061. https://doi.org/10.2307/2937956

[10] Thaler, R.H. and Sunstein, C.R. (2008) Nudge: Improving Decisions about Health, Wealth, and Happiness. YYale University Press, New Haven.

[11] What Is Crowd Psychology? http://wisegeek.com

[12] Tversky, A. and Kahneman, D. (1981) The Framing of Decisions and the Psycholo- 
gy of Choice. Science, 211, 453-458. https://doi.org/10.1126/science.7455683

[13] Kahneman, D., Knetsch, J.L. and Thaler, R.H. (1990) Experimental Tests of the Endowment Effect and the Coase Theorem. Journal of Political Economy, 98, 1325-1348. https://doi.org/10.1086/261737

[14] Beggan, J. (1992) On the Social Nature of Nonsocial Perception: The Mere Ownership Effect. Journal of Personality and Social Psychology, 62, 229-237. https://doi.org/10.1037//0022-3514.62.2.229

[15] Peters, F.H. (Translation) (n.d.) Aristotle: The Nicomachean Ethics Book IX.

[16] (2018) Why Nobody Wants a New Energy Vehicle. http://m.elecfans.com

[17] Lin, T.C.W. (2012) A Behavioral Framework for Securities Risk.

[18] Empirical Policy Analysis Unit, Environment and Economy Integration Division, OCED (2012) Environment Directorate Behavioral Economics and Environmental Policy Design.

[19] Brown, Z. (2013) OCED Annex: An Experiment to Test the Effect of Defaults on Thermostat Settings of OCED Employees.

[20] The Green Deal? https://en.wikipedia.org/wiki/The_Green_Deal

[21] Green Deal: Energy Saving for Your Home or Business-GOV.UK.

[22] Hu, Q. (n.d.) How Can We Use Behavioral Economics to Promote Energy Saving Behavior of the Residents through Promoting the Purchase of Energy-Saving Devices in China?

[23] Zhao, Q. (2013) Huimin Project: End in Disputes. Dian Qi, 222, 56.

[24] Vaughan, A. (2013) Four Out of Five People Have Not Heard of Green Deal, Poll Finds. The Guardian, London.

[25] Green Deal Proposals for Home Upgrades Still Lack Credibility. http://Endsreport.com

[26] Cuff, M. (2012) M\&S and Tesco Missing from List of First Green Deal Providers. The Guardian, London. 